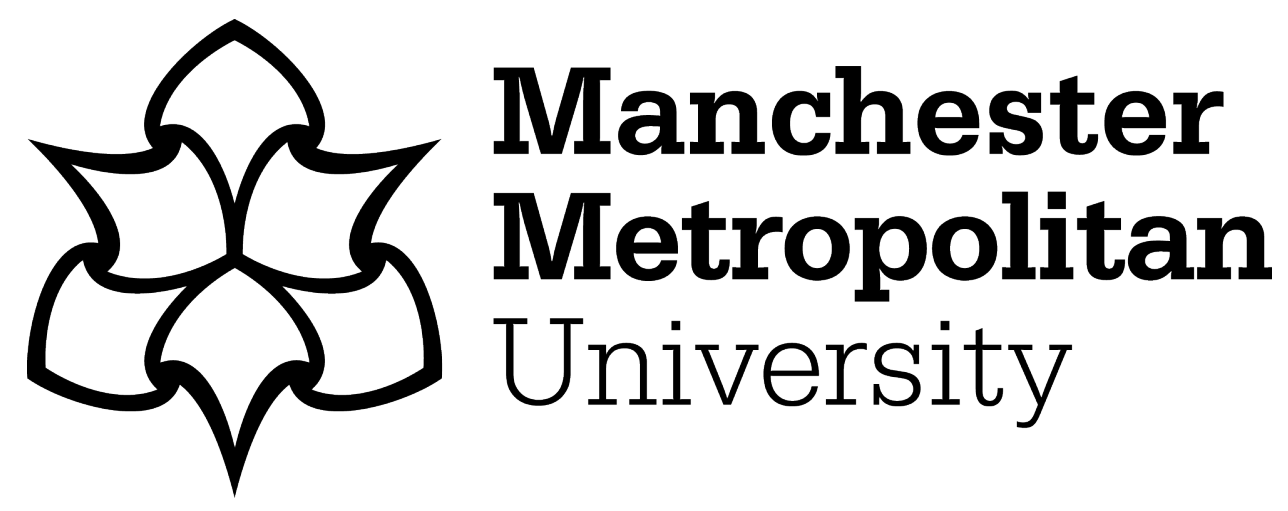

Ilott, Sarah (2018) "How is these kids meant to make it out the ghetto now?" Community cohesion and communities of laughter in British multicultural comedy. Journal of Commonwealth Literature, 53 (2). pp. 211-222. ISSN 0021-9894

Downloaded from: https://e-space.mmu.ac.uk/619560/

Version: Accepted Version

Publisher: SAGE Publications

DOI: https://doi.org/10.1177/0021989416687351

Please cite the published version 


\title{
"How is these kids meant to make it out the ghetto now?": Community cohesion and communities of laughter in British multicultural comedy
}

\section{Sarah Ilott (Teesside University, UK)}

\begin{abstract}
This article uses readings of Mark Mylod's Ali G Indahouse, Joe Cornish's Attack the Block, and Chris Morris's Four Lions to argue against a political trend for laying the blame for the purported failure of British multiculturalism at the hands of individual communities. Through my readings of these comic films, I suggest that popular constructions of "community" based on assumptions about cultural and religious homogeneity are rightly challenged, and new communities are created through shared laughter. Comedy's structural engagement with taboo means that stereotypes that have gained currency through media and political discourse that seeks to demonize particular groups of young men (the Muslim or the gangster, for example) are foregrounded. By being brought to the forefront and exposed, these stereotypes can be engaged and challenged through ridicule and demonstrations of incongruity. Furthermore, I suggest that power relations are made explicit through joking structures that work to include or exclude, meaning that the comedies can draw and redraw communities of laughter in a manner that effectively challenges notions of communities as discrete, homogeneous, and closely connected to cultural heritage. The article works against constructions of British Muslims as the problem community par excellence by using multicultural discourse to contextualize the representation of British Muslims and demonstrate how the discourse has repressed the role of political, social, and economic structures in a focus on "self-segregating" communities.
\end{abstract}

\section{Keywords}


Community, British Muslims, comedy, multiculturalism, Ali G, Four Lions, Attack the Block, laughter

The post-9/11 period has seen the release of a number of comedy films that engage critically with British multiculturalism. Mark Mylod's Ali G Indahouse (2002), Chris Morris's Four Lions (2010), and Joe Cornish's Attack the Block (2011) each push aspects of the realities of British multiculture to comic extremes in a manner that highlights and thereby critiques. This serves to challenge a popular discourse — bolstered by both politicians and the media — that places the blame for the purported failure of British multiculturalism on individual communities rather than on political and economic systems that combine with imperialist legacies to create disenfranchisement and alienation. It is the argument of this article that such communities are increasingly (and problematically) identified along religious lines following the terrorist attacks of September 112001 and the subsequent "war on terror", as well as disturbances closer to home. The comedies considered here, whilst critiquing and undermining a dominant discourse of British multiculturalism centring on the responsibility of individual "communities" that takes hold in the period following 2001, also enable the redrawing of boundaries of "community" through the engendering of collective laughter.

Despite framing this paper in terms of shifts in attitudes that begin to take place in 2001, and that relate in particular to British Muslims, I have deliberately chosen to include discussion of two comedies that bear no direct relation to $9 / 11$ or British Muslims (Ali G Indahouse and Attack the Block). In so doing, I hope to illustrate that whilst political discourse increasingly focuses on one "community" (British Muslims) and one conflict (Britishness versus Islam) in its construction of British multiculturalism, the films collectively demonstrate elisions in the discourse and effectively reframe the debate to include questions of class and race that are repressed by the framing of "self-segregating" 
Muslim "communities" as the problem. It is, I believe, an important academic and political choice to consider the representation of British Muslims in the broader context of multicultural discourse, so as not to perpetuate a system that at once accuses British Muslims of (self-)segregation and reproduces this through its methodological focus on one group in isolation. The events of $9 / 11$, and the subsequent upsurge in an already extant Islamophobia, have played a significant role in entrenching a focus on Muslims in British political discourse as a problem to be solved. However, what I want to suggest through my readings of these three comedies, is that while $9 / 11$ is clearly a defining moment in the popular consciousness, it is important not to lend too much weight to it as a tipping point that in turn risks dehistoricizing a narrative of the stigmatization and disenfranchisement of migrant communities in Britain that in reality by far predates September 112001 . By considering the rhetoric of British multiculturalism more broadly, I seek to avoid pandering to Conservative governance and the popular media who would prefer to posit the actions of Muslims themselves as the cause of contemporary Islamophobia and as necessitating tougher policies for the management of multicultural Britain, which effectively positions Islamophobia as the effect rather than the cause of the self-segregation of which British Muslims are often accused.

I turn now to events closer to home that have shaped the way that multicultural Britain has been constructed in political and media discourse, particularly in relation to British Muslims and the notion of "communities". In May 2001, there were outbreaks of violence between white and Asian youths in Oldham, Greater Manchester, which were shortly followed by similar riots in Burnley and Bradford. Varying economic, social, criminal, and racist factors were referenced as catalysts for the riots (see Casciani, 2006). Nevertheless, the diversity of possible causes was largely played down in the official report commissioned by the Department for Communities and Local Government, and produced by 
the Community Cohesion Research Team led by Ted Cantle (2001). The focus was instead on a rhetoric of "parallel lives" (CCRT, 2001) and what Home Secretary David Blunkett later summarized as the "failure to produce cohesive communities and common citizenship" (Blunkett, 2001).

Hannah Jones's excellent Negotiating Cohesion: Uncomfortable Positions in Local Government explores the emergence of community cohesion as a "policy catchphrase", and one that is poorly defined and inconsistently applied (2013: 2). Jones notes that in the Local Government Association's document that first defines the term "community cohesion", there are slips in usage, the term "sometimes being cause, sometimes goal, sometimes overarching measure, and sometimes all three" (2013: 3). Her most important intervention is to note that the policy works by putting the onus on individuals to "value diversity in the ways expected of them" (without being forced to do so), meaning that "legacies of discrimination and oppression institutionalised in housing, education or employment — are removed from the equation; a lack of community cohesion is ultimately seen as a failure of individuals and communities, rather than society as a whole" (2013: 4-5). Following in Jones's footsteps, this paper recognizes the importance placed by governing bodies on ambivalently defined political concepts of "community" and "cohesion" that work to shift emphasis away from structural and institutionalized methods of disenfranchisement. It is important to note, that whilst official definitions of community and community cohesion policies are ambiguous about particular targets or foci, practices and discourse have evolved to position British Muslims as the problem community par excellence, and placed the blame and responsibility for the failure of multiculturalism with them, rather than with society and its structures at large. In a bid to challenge this discourse, I consider three films that present different constructions of community, and that critique and expose the realities of British multiculture frequently repressed by popular and political discourse. 
Comedy is an ideal vehicle for revealing what normative discourses about

multiculturalism attempt to repress, due to the form's engagement with taboo and stereotypes. It is a genre characterized by humour and the integration of jokes. The genre's reliance on humour - the ability to see a situation as funny, and to construct that funniness in a particular way (as childish, bathetic, or absurd, for example) — shifts the discursive field of the British multiculturalism that is represented therein. Rather than casting multiculturalism as a failure, with Britain reaching its inevitable nadir resultant upon the fatal flaws of hubris or lack of judgement represented by various attempts to assimilate or integrate cultural and ethnic difference, comedy functions to allow audiences to "derive great pleasure" from a subject that might otherwise be deemed tragic, by injecting the situation with humour and drawing attention to inherent incongruities and absurdities (Stott, 2005: 12). Power relations are also made explicit through the jokes that are central to the comedy format; these are "communicative acts which play a significant role in social exchanges — a medium through which society disseminates and generationally transmits its dominant attitudes towards outgroups" (Howitt and Owusu-Bempah, 2009: 51). The location of power is made evident through the collusion of the teller and audience in exclusion of the butt of the joke, a process that allows for new modes of affiliation and identification. Where stereotypes and power relations are implicit and often (purposefully) disguised in political discourse, the form and dynamic of the joke means that these elements are brought to the forefront. Dennis Howitt and Kwame Owusu-Bempah make this evident through comparison of a joke taken from a racist website (“Q: What's the definition of Mass Confusion? A: Father's day in Harlem") to a statement ("In Harlem on Father's day the mass of people are confused"). As they suggest, when the joking structure is removed, "the statement becomes harder to interpret, it does not conform to the 'rules of the game' [...]. Expressing the stereotype using a common joke structure actually facilitates the recognition of the message!" (2009: 55-56). The comedies I 
consider below undertake at a grander scale similar work to the above joke through the repeated inclusion of visual and linguistic jokes that redeploy stereotypes about ethnic and religious minority groups; this occurs, however, not to reinforce the stereotypes (as is the case with this racist joke), but to point to their existence in popular consciousness and thereby begin to critique them. It is useful to remember at this point that in Homi Bhabha's pioneering work on representations of the "other", he suggested that in order to displace rather than simply dismiss — a stereotype, it is necessary to "engage with its effectivity" (2000: 67). Where the Muslim and the gangster are implicitly made "other" through political discourse and media representations relating to British multiculturalism, their comic representation in the films considered here reveals and engages with these stereotypes and hierarchical constructions, pointing to their currency in contemporary discourse.

Furthermore, comedy has a role in creating new affiliative communities. Political and media discourse frequently creates an "us versus them" dynamic in which British Muslims are cast as "other" to mainstream British society. ${ }^{1}$ Such representations confirm the political rhetoric around homogeneous "communities". By contrast, the work of joking has the power to create communities that breach familiar us/them binaries. Marie Gillespie indicates the community-building potential of jokes by suggesting that "those who share a joke belong to a community, however temporary, of people alike enough in outlook and feeling to be joined in sharing a joke" (2003: 93). Similarly, Howitt and Owusu-Bempah aver that "joker and listener both have active roles in making the joke work" (2009: 49). Comedy, as such, can potentially unite the audience of films with the tellers of the jokes, thereby creating an empathetic space in which to address topics often constructed as taboo. As has been evidenced on numerous occasions, the creation of empathy is an important tool for countering the often alienating effects of media discourse. Nowhere has this been more recently apparent than in the case of Aylan Kurdi, the Syrian child refugee whose image washed up dead on 
Turkish shores briefly shifted public attitudes in Europe towards a refugee crisis previously (and subsequently) constructed in terms of pressures on European states as opposed to considering the lives of those fleeing life-threatening danger. This reiterates Richard Dyer's important formulation that "How we are seen determines in part how we are treated; how we treat others is based on how we see them; such seeing comes from representation" (1993: 1). The creation of a "community of laughter" through an audience's identification with the tellers of jokes marks an important move in seeing those often demonized in the media (such as gang members and Muslims) as subjects worthy of empathy. This reverses patterns of exclusion and temporarily re-centres the lives and struggles of otherwise marginalized and alienated groups of young men on which each of the comedies focuses. These new communities of laughter are undeniably temporary, as the ambivalence of comedy as a medium means that affiliations are frequently redrawn, even within the space of one film, or one joking exchange. As with the Bakhtinian construct of a "second life, organised on the basis of laughter", these comedies cannot be interpreted as having radical political implications, as they serve as an interlude to the persistence of the first life of a demonizing and alienating mainstream media (Bakhtin, 1994: 198). Yet whilst history teaches us that the political effects of laughter in bringing about widespread social change are negligible (the powerful rarely lose their hegemonic status as a result of satire), the psychological effects of constructing peoples as "us" rather than "them" on the basis of shared laughter and challenged stereotypes are perhaps more enduring.

Ali G Indahouse (Mylod, 2002) begins to counter the idea of homogeneous communities through a focus on gang members and their networks of shifting affiliations, using the ambivalence of the shifting relations enacted through joking exchanges as a foil. The film draws on a character originally created and performed by comedian Sacha Baron Cohen for Channel 4's The 11 O'Clock Show (1998-2000) and Da Ali G Show (2000-2004). 
The character is a white suburban youth who passes as black and styles himself according to an American hip hop scene with a London Jamaican-inflected accent. The film documents the appointment of this local posse ringleader Ali G to MP for Staines due to his perceived incompetence, as part of the Chancellor's evil ploy to overthrow the Prime Minister (the Chancellor recommends that the Prime Minister employ incompetent Alistair Graham in a bid to affect poll ratings detrimentally and lead to calls for the Prime Minister's resignation). However, Ali G's ability to "keep it real" with a series of policies to relax drug laws and allow more "fit refugees" into the country makes the Prime Minister and his government more popular than ever, leading the Chancellor to take more drastic measures to undermine his authority. Disillusioned with the Chancellor's underhand tactics that force the Prime Minister to step down, Ali G takes it upon himself to expose the corruption of the political system, resulting in a farcical sequence that involves the united gangs of East and West Staines — dressed in neon shades of khaki — wiring their cars together and forming a human chain to short-circuit a safe holding secret documents, the revelation of which will expose the Chancellor as a crook.

The film engages with and deconstructs the idea of communities as homogeneous and tightly bordered through its focus on neighbourhood gangs. A specific fear of gangs bearing a resemblance to those found in American "ghettos" was brought to the forefront in Trevor Phillips' memorable warning about Britain “"sleepwalking' into racial and religious segregation" (Phillips, quoted in Anon, 2005). However, Mylod's film is prescient in its challenge to the threat such gangs are seen to pose, and in highlighting the structural inequalities that create the cultures of disempowerment and unemployment in which the gang culture is shown to thrive. The film's initial conflict operates between the gangs of East and West Staines, who have embarked upon a turf war over a particular patch of playground, and who demonstrate their affiliation through colour-coded uniforms and repeated proclamations 
that their own territory is "best". Conflict between the gangs is largely verbal and/or performative, and devoid of physical violence. With the exception of the consumption of quantities of drugs and confiscated pornography, members of the gangs are mainly lawabiding, as is indexed through a car race in which both drivers ensure not to exceed the speed limit, which serves to undermine any sense of threat. Yet devotion to an individual gang and the super-local area in which it is based is superseded when the various gangs unite to confront the government (ostensibly in opposition to plans to close the local John Nike Leisure Centre), a manoeuvre that importantly reiterates that an individual will have multiple and shifting affiliations and values. ${ }^{2}$

The shifting nature of affiliations is also made evident through the joke work, as ambivalent humour throughout the film draws and redraws the boundaries of inclusion and exclusion. Failure to acknowledge some jokes as jokes disempowers the tellers, such as when Ali G deems his rival gang leader's “yo mum so fat” joke as unfair, attributing his mother's weight to a glandular defect and denying the intellectual superiority implied by a successful joke. ${ }^{3}$ Similarly, sexist and/or homophobic jokes are frequently presented in ways that ironize the attitudes expressed. Ali G, for example, reprimands another man in the following terms: "that is a very sexist way to talk about these bitches". The juxtaposition of sexist and antisexist language in the same statement is destabilizing and encourages laughter at Ali G for the unacknowledged sexism that renders him ridiculous. To laugh at the sexist sentiment would be to misinterpret the joke, and the joke-work thereby excludes sexists in this instance, casting them outside the community of shared laughter. Though the film's plot works to teach Ali $\mathrm{G}$ greater respect for his girlfriend, Julie, the end credits portray the Chancellor forced to dress in women's clothing and dance for Ali G in a manner that implies that femininity is inferior and a source of potential ridicule when exhibited by men, which sends quite a different message to the previous exclusion of sexists through the joke-work. This 
combination of sexist and anti-sexist messages perpetually draws and redraws the boundaries of inclusion and exclusion, forcing audiences actively to consider their relationship to the power structures set up within jokes, and their desire to acknowledge them with laughter or dismiss them through stony silence. Comedies such as this place more power in the hands of the audience by making stereotypes and power structures explicit, and thereby forcing audiences to acknowledge their role in upholding or upturning these structures and representations as laughter becomes a form of collusion.

In its focus on the local community of Staines, Ali G Indahouse turns the emphasis in political discourse on the failure of individuals and communities on its head. Instead, emphasis is placed on the damage inflicted on local communities through funding cuts. Hearing news of plans to close the leisure centre while in the middle of running one of his "Keep it Real" clubs for young boys (a version of Scouts for aspiring gangsters), Ali G sums up the situation as follows:

How is these kids meant to make it out the ghetto now? [...] Do you know what this centre means to them? And to me? This is the spiritual home of the West Staines Massiv. This is like what Mecca is to the Jews. It's like what Kentucky is to chickens.

The humour of Ali G's misunderstanding of Islam and Judaism (and of the likely fate of Kentucky chickens) works to undermine the seriousness of his claim, yet the "ghetto" culture is nevertheless explicitly tied to the withdrawal of the economic capital and community hub represented by the leisure centre and its activities. This critique of the removal of economic and cultural capital is increasingly poignant as cuts to already-deprived regions become ever more commonplace under the current Conservative government's austerity programme (such 
as the relocation in 2016 of archives from the National Media Museum in Bradford to the Victoria and Albert Museum situated in the wealthy Knightsbridge region of London).

Cornish's Attack the Block similarly focuses on gangs and their relations with local and national structures as a means of interrogating notions of community cohesion. I read this film as extending the ethos of Ali G Indahouse by intervening in ideas about victimhood; it deconstructs the notion that mainstream society is the victim of problem communities by foregrounding ways in which communities are victims of state structures. In so doing, the film also importantly foregrounds the category of race that is frequently lost in euphemistic constructions of community (see Lentin and Titley, 2011: 43). Merging the genres of comedy and sci-fi, the film follows the haphazard attempts of a Brixton gang to deal with an alien invasion on their local estate. It is a film about the coming together of the residents of a tower block despite initial divisions. Though the film commences with the gang's mugging of a white nurse named Sam, they eventually reach a point of reconciliation when the gang protect Sam and return her stolen ring, whilst she tends the wounds of the aliens' victims. Sam and the gang stand in solidarity against the alien attack, a psychotic drug baron named Hi Hatz, and eventually the police. Working against Hi Hatz's oft-repeated mantra that "this is my block", the gang demonstrate the necessity of working together to occupy and reclaim the space under threat. However, there is little in the way of a happy ending for the gang members, who are briskly incarcerated in a police van, sure to be charged (as they have previously predicted) with "everything that happened everywhere in the ends tonight". The film implicitly challenges a discourse that sees problem "communities" as responsible and mainstream British society as the victims of those who refuse to integrate or assimilate due to living "parallel lives". This is enabled predominantly through the representation of Sam as a victim of mugging at knifepoint at the hands of the teenage gang, with quick cuts between shots and reverse shots that increase the tension as the gang closes 
in. Yet this initial scene functions thematically to foreground wider experiences of victimhood, encouraging a revaluation of the term to take into consideration impersonal systems that can similarly discriminate, ostracize, and victimize. ${ }^{4}$ Economic deprivation is foregrounded from the outset as a motivation for the gang's actions in mugging Sam. When the gang rifle through her wallet and realize she is a nurse, one of the gang asks Moses, "why you always picking on poor people, bruv?", demonstrating their need for money and the beginnings of an identification with their victim. The young men's comparative poverty is also indicated when Sam enters Moses' apartment: the camera follows Sam's gaze and lingers on the squalor that she witnesses; her pathos is evident when she finds out that Moses lives with an uncle who "comes and goes. Mainly goes". Seeing both Sam and her muggers as victims deconstructs a binary that would place them in oppositional positions and instead foregrounds a chain of victimization, in which Sam is the final rather than the only link. A focus on markers of class and poverty also serves to highlight what Rehana Ahmed refers to as "the centrality of class to multicultural politics in Britain" - a centrality that is often obscured through a focus on "cultures" and "communities" (2015: 10). An inclusion of class in debates about British multiculturalism is particularly pertinent when considering that "the South Asian Muslim diaspora" — around whom rhetoric surrounding "communities" and "parallel lives" became more pronounced in the wake of the 2001 riots — "has consistently occupied a position at or near the bottom of Britain's social scale", a fact that is barely acknowledged through a discourse that apportions responsibility and blame with the "communities" themselves (Ahmed, 2015: 18).

What is crucial in the adolescents' representation as victims, however, is that blame is not placed on individuals, but on a social and systemic violence that has alienated and disenfranchised this group of young men. This engenders a revaluation of victimhood by highlighting the institutionalized socio-political legacies of racism: reduced opportunity and 
economic deprivation that have engendered the alienation of certain migrant communities, and the prejudice and disproportionate violence of the police when dealing with the gangsters. The teenagers' experience of alienation (and parallels between the aliens and the gang that they pursue are drawn throughout) ${ }^{5}$ is foregrounded in a scene in which the gang discusses what to do and recognizes that contrary to Sam's instincts they cannot turn to the police for help, as "they arrest us for nothing already". Moses even begins to speculate as to whether the aliens have been sent by the government, as yet another means of killing "black boys" (all but one of the gang members are black or mixed race). Indeed, attention is drawn to race at a number of points in the film, including in the young men's description of the aliens as "black; too black to see" and "the blackest black ever". I read this reference to being "too black to see" as a gesture towards the invisibilization of race as a category in contemporary multicultural discourse. In their work on the shifting discursive field of multiculturalism, Alana Lentin and Gavan Titley argue that "The language of community was also inflected with a post-racial sense, allowing public policy actors to discuss problem populations through known-in-common coordinates, but without having to specifically name and engage them" (2011: 44). The terminology of such discourse effectively disavows the connection between Britain's imperial history and its multicultural present; it represses Britain's psychological and material colonial legacies by euphemistically foregrounding "cultures" and in so doing disguises links to groups previously discussed (and protected) with reference to race and racism.

Finally, I turn to Chris Morris's Four Lions, which engages more explicitly with the context of a post-2001 Britain (in terms of increased Islamophobia and the local contexts of riots in the North), yet deconstructs mainstream rhetoric regarding "parallel" lives lived by easily recognizable communities divided along ethno-religious lines. It is an outrageous comedy that engages the figures of suicide bombers that do not conform to type as "cold 
reptilian killers" (Morris, quoted in Brooks, 2010) but enact their suicide mission through a series of slapstick mishaps and misunderstandings. On the surface, it actually seems less concerned than the other two films discussed with the institutional and structural causes of the alienation of the young men that it takes as subject; there is little in the way of back story to the men preparing to embark on a suicide mission, with the exception of Omar, whose home life with his wife and son — and work life as a security guard — are given some screen time. However, the backdrop to the men's lives is suggested through the documentary Lost Boys (2010) - made by Associate Producer Afi Khan and included in the film's extras which gives more insight into the context and research behind the feature film. Set in Nelson, East Lancashire, the documentary investigates the lives of young British Asians daily facing the racism and nationalism of British National Party supporters that are fuelled by poverty, crime, and drug and alcohol abuse. Asked why there is so much hatred, one young man answers, “Because they want us out. They don't want to know us, they don't want to know our religion [...] that's why most Asian lads just go for anyone they see." The inclusion of this documentary in the DVD extras suggests that it is intended as a partner piece to the film; although it is made by Khan rather than Morris, its content is reflective of the "years of detailed research" undertaken by Morris (see Brooks, 2010) and I therefore read it as providing the largely absent socio-political context in terms of the men's backgrounds and experiences. Concerned with a group of men largely of South Asian Muslim heritage (with the exception of a white convert named Barry), this film most clearly engages with the context of an Islamophobic post-9/11 culture in Britain in which British Muslims are constructed as internal "others", and with the rhetoric of communities that emerged following the spate of riots in northern towns during the summer of 2001.

However, I want to suggest that whilst engaging with the context out of which the discourse of "communities" and "parallel lives" emerged, the film deconstructs the notion of 
community breakdown driven by ethnic or religious divisions, as groups and individuals that come into conflict are not clearly distinguished into British Asians/Muslims versus a white, non-Muslim working class. Divides between those identifying as Muslim are exposed through a constructed opposition between the values and practices of Omar and his band of would-be terrorists and his brother's more scholarly circle, who are frequently ridiculed for their peaceful and cerebral interpretation of Islam and for their poor treatment of women (whom they lock in a cupboard that brother Ahmed insists is a "small room"). The apparent incongruity of Barry's insistence that "the mosques have lost it", which engenders his desire to bomb the mosque and thereby "radicalise the moderates", also highlights schisms between those identifying as Muslim, as does Hassan's preference for a "jihad of the mind" that is promptly dismissed as a mere "gesture" by Barry in his pursuit of "action". A united opposition against (or disapprobation from) the white working-class residents is also undermined: Omar has a friendly relationship with his white co-worker Matt (who goes on to defend Omar's honour after his death); a hippy neighbour called Alice enjoys a friendly conversational relationship with the group of British Muslim men (despite being duped into thinking that they are a band); and Barry — as a white convert to Islam — destabilizes binaries discursively constructed between British Muslims and the white working class.

I read Barry's function in the film as having particular significance when it comes to foregrounding the performative nature of religious practice and a divorce between religion and cultural heritage. Though Barry is a Muslim convert and surrounded by Muslims of a South Asian heritage, he does not identify with or fetishize a South Asian culture. Unlike his friends, he cannot speak Urdu and at points he uses derogatory language to suggest his superiority to the Pakistanis that Omar and Waj plan to visit at the training camp, saying "we don't need some Paki Steptoe telling us when to go". The incongruity of the image evoked through Barry's comment is designed to undermine and dismiss the seriousness of the 
Pakistanis' involvement. However, Barry's exclusion from the group in terms of a shared South Asian culture is represented as leading to his extreme performance of his religious identity and his dismissiveness of those he terms "moderate" Muslims. Barry warns: "the mosques have lost it, brother. They're full of losers and spies. These are real bad times bro. Islam is cracking up. We've got women talking back. We've got people playing stringed instruments. It's the end of days." The hyperbolic language indexes the lengths to which Barry is prepared to go to persuade the others to accept his performance of Muslim identity, and furthermore that he is "already in the Mujahideen" and the "most Al Qaeda one 'ere". Barry's Muslim identity is not seen as innate or following naturally from his cultural heritage (as is often the case in the representation of South Asian Muslims), which enables a foregrounding of identity as performative, an aspect that is reflected in other moments of the film, such as the shooting of the jihadi video, and the men's pretence to Alice that they are members of a band. This effectively serves to challenge a rhetoric that constructs communities as bearing a simplistic and essentialist relationship to cultural heritage. Furthermore, Barry's performance of a particular form of Muslimness verges on mimicry, defined as it is by the three characteristics that Bhabha identifies as necessarily accompanying acts of (colonial) mimicry: slippage (his unconventional interpretations of scripture), excess (his hyperbolic language and aggressive postures) and difference (his whiteness) (Bhabha, 2000: 86). Barry's “desire to emerge as 'authentic"” jihadi through his performative repetition of the extremist Muslim identity with which he identifies, in fact demonstrates the ambivalence of that identity, which thereby functions to "disrupt its authority" (Bhabha, 2000: 88). As such, the power and fear conventionally invoked by the character of the Muslim extremist is mocked and undermined.

Joking is used as a means of power play throughout the film, particularly in sparring matches between Omar and Barry. While Barry attempts to assert his authority in Omar's 
absence by recruiting Hassan ("the Mal") and forcing Waj and Faisal to perform perverse acts involving their own genitalia as a means of encouraging "submission" (which is the literal translation of Islam), Omar fights back with a form of humour designed to undermine and exclude Barry. A joke delivered in Urdu that translates as "How's your Urdu then, you monkey bollock duster?" serves to exclude Barry from the community of laughter created by Waj, Faisal, and Omar in the car driving to the airport. Similarly, Omar takes Barry's extreme plans to bomb the mosque so as to radicalize the moderates as a source of ridicule, encouraging Barry to punch himself in the face as an analogy for his absurd proposition, until a nosebleed causes Omar to jibe that "there's Sufi Muslim councils coming out of your nose". Omar is, by the end, acknowledged leader of the group, having used joking as a means of empowerment and to redraw the lines of inclusion to exclude and demean Barry. As such, jokes are used to "define social categories and group boundaries incorporating some as insiders and others as outsiders, delighting some and offending others" (Gillespie, 2003: 93).

The community-building function of laughter identified by Gillespie can extend beyond the fourth wall, I would argue, to include or exclude viewers at home or in the cinema, as comedy requires the active engagement of the audience for the format to take effect. If there is no laughter (or implicit acknowledgement of the existence of humour) then the comedy fails. I suggest, therefore, that these comedies are doing important work, not only in foregrounding the aspects of multicultural reality that are frequently repressed through discursive constructions that emphasize the role of individuals and communities as opposed to structural inequalities, but by positioning audiences as active consumers of the stereotypes and representations served up to them. This positioning of audiences as active is significant as it potentially empowers viewers to challenge damaging stereotypes reiterated elsewhere. The focus on alternative constructions of community is particularly pertinent given the increasing demonization of Muslims in Britain since 2001, which has been bolstered by 
media representations and political discourse. By considering the three comedies collectively, it becomes apparent that what the young men in Four Lions seem to find in a violent and extremist version of Islam is an apparent source of power in the face of disenfranchisement; this search for power is comparable to the performance of black masculinity by the unemployed white men in Ali G Indahouse or the resort to violence by the "alienated" gangs in Attack The Block. Drawing comparisons between these groups of men serves to remedy a focus on Muslims that has had the effect of downplaying racism and economic deprivation as factors for exclusion, which in turn risks dehistoricizing the stigmatization of migrant communities that by far predates 2001 . To challenge rhetoric that problematically centres $9 / 11$, I have therefore read these comedies not as part of a world that came into being as the planes hit the Twin Towers, but as commenting upon the elisions of multicultural discourse and a longer history of racialized disenfranchisement and alienation in Britain. I argue that this is effected in the comedies by tackling the taboo topics of race, racism, and economic hardship glossed over by multicultural discourse's negative focus on "communities".

\section{References}

Ahmed R (2015) Writing British Muslims: Religion, Class and Multiculturalism. Manchester: Manchester University Press.

Ali G Indahouse (2002) Directed by Mark Mylod [Film]. UK: Universal Pictures StudioCanal Working Title.

Anonymous (2005) Britain "sleepwalking to segregation". Guardian. Available at: http://www.theguardian.com/world/2005/sep/19/race.socialexclusion (accessed 21 April 2016).

Anonymous (2006) Straw's veil comments spark anger. BBC. Available at:

http://news.bbc.co.uk/1/hi/uk politics/5410472.stm (accessed 22 April 2016). 
Attack The Block (2011) Directed by Joe Cornish [Film]. UK: StudioCanal Features Film4. Bakhtin M (1994) Rabelais and His World [excerpt]. In: Morris P (ed.) The Bakhtin Reader. Edward Arnold: London, pp. 194-244.

Bhabha H (2000) The Location of Culture. London: Routledge.

Brooks X (2010) Chris Morris: “Bin Laden doesn’t really do jokes.” Guardian. 1 May. Available at: http://www.theguardian.com/culture/2010/may/01/chris-morris-fourlions-interview (accessed 31 January 2015).

Casciani D (2006) Q\&A: 2001 northern town riots. BBC. 1 June. Available at: http://news.bbc.co.uk/1/hi/uk/5032166.stm (accessed 18 December 2014).

Community Cohesion Review Team (2001) Community cohesion: A report of the Independent Review Team, chaired by Ted Cantle. Available at: http://resources.cohesioninstitute.org.uk/Publications/Documents/Document/Downloa dDocumentsFile.aspx? recordId=96\%26file=PDFversion (accessed 16 December 2014)

Dyer R (1993) The Matter of Images: Essays on Representation. London: Routledge. Fishwick C and Marsh S (2016) What British Muslims really think about Channel 4's Show. Guardian. Available at: http://www.theguardian.com/uk-news/2016/apr/14/whatbritish-muslims-really-think-about-channel-4s-show (accessed 15 April 2016). Four Lions (2010) Directed by Chris Morris [Film]. UK: Film4.

Gillespie M (2003) From comic Asians to Asian comics: Goodness Gracious Me, British television comedy and representations of ethnicity. In: Scriven M and Roberts E (eds) Group Identities on French and British Television. New York: Berghahn, pp. 93-107. Howitt D and Owusu-Bempah K (2009) Race and ethnicity in popular humour. In: Lockyer S and Pickering M (eds) Beyond a Joke: The Limits of Humour. Basingstoke: Palgrave Macmillan, pp. 47-64. 
Ilott S (2015) New Postcolonial British Genres: Shifting the Boundaries. Basingstoke:

Palgrave Macmillan.

Jones H (2013) Negotiating Cohesion: Uncomfortable Positions in Local Government.

Bristol: Policy Press.

Lentin A and Titley G (2011) The Crises of Mulitculturalism: Racism in a Neoliberal Age.

London: Zed Books.

Morey P and Yaqin A (2011) Framing Muslims: Stereotyping and Representation after 9/11.

Cambridge, MA: Harvard University Press.

Pearson A (2014) Rotherham: In the face of such evil who is the racist now? Telegraph.

Available at: http://www.telegraph.co.uk/news/uknews/crime/11059138/Rotherham-

In-the-face-of-such-evil-who-is-the-racist-now.html (accessed 21 April 2016).

Purdie S (1993) Comedy: The Mastery of Discourse. Hemel Hempstead: Harvester

Wheatsheaf.

Stott A (2005) Comedy. Oxon: Routledge.

Watt N (2016) Sadiq Khan says there is "question to be asked" about use of hijabs in London.

Guardian. Available at: http://www.theguardian.com/politics/2016/apr/14/sadiq-khan-

question-to-be-asked-about-hijabs-veils-london (accessed 19 April 2016).

Younge G (2000) Is it cos I is black? Guardian. 12 January. Available at:

http://www.theguardian.com/world/2000/jan/12/race (accessed 18 December 2014).

\footnotetext{
${ }^{1}$ For more on the conventions of "framing" Muslims in contemporary media, see Peter Morey and Amina Yaqin's excellent Framing Muslims: Stereotyping and Representation after 9/11 (2011).
} 
${ }^{2}$ This is an important reminder given the fact that in the case of British Muslims, the religious affiliation is frequently constructed as superseding the national affiliation at all points. As teenage British Muslim Ibrahim Ilyas notes in his response to the misleading representations on Channel 4's What Do British Muslims Really Think?, "Many British Muslims hold traditional values that others of other faiths may hold such as disagreeing with same-sex marriage. Yet overwhelming evidence points to the fact that we are a patriotic community and have a strong affiliation and sense of belonging to this great nation" (Fishwick and Marsh, 2016).

${ }^{3}$ For more on the psychoanalytic and linguistic structures with which we can interpret joking mechanisms, see Susan Purdie (1993).

${ }^{4}$ It is telling that directly after Sam refers to the gang members as "fucking monsters", the camera cuts to an image of an alien being dragged along with a knife in its back, undermining a binary between monsters and victims by clearly marking it as both.

${ }^{5}$ I explore the parallels between aliens and migrant communities further in my monograph (Ilott, 2015: 162-163). 